sonally relied on this alone, and have recommended this proceeding to many patients. When facing a cold east wind, or breathing quickly the night air, I never quite close my mouth, but purposely keep the lips a trifle parted, and at the same time curl up my tongue towards the roof of my mouth until the tip reaches as far back as the soft palate, and I gently press the arched under surface of the tongue in some degree against the hard palate (a little practice soon makes this easy to do). The cold air then, as it enters the mouth, strikes against the under surface of the tongue, as well as the floor and sides of the mouth, and is made to pass in a somewhat circuitous manner between the sides of the tongue and the buccal mucus membrane of the pharynx, being thereby warmed in its course, so that by the time it reaches the larynx it is nicely rid of chill, and does not excite cough and catarrh. At the same time a certain quantity of air, of course, finds its way through the nasal passages to the chest, and it is obvious that a larger quantity of cold air can be effectually warmed by this method of procedure than by relying on either the nose or mouth alone. That the large blood-supply of the tongue renders this organ an excellent air warmer must be obvious to all.

\section{The Sense of Taste in the Larynx.}

For many years it has been known to histologists that the specific end-organs of taste, nameiy, the taste-bulbs, occur on the posterior or inner surface of the epiglottis, but up till now the physiological proof of the existence of the sense of taste in the epiglottis has not been forthcoming. Michelson, according to the British Medical Journal, Aug. 8, under Langendorff's direction, made a number of experiments, which show that the inner surface of the epiglottis is endowed with taste. A Schroetter's laryngeal sound, tipped with a solution of quinine or saccharine, was introduced into the larynx, and the drop of the sapid substance was cautiously brought into contact with the inner surface of the epiglottis. Positive results were obtained, which were controlled by the sensation - electrical taste - known to be produced by electrical stimulation. It seems, therefore, proved that a part of the nerve fibres passing to the larynx are nerves of taste.

\section{LETTERS TO THE EDITOR.}

** Correspondents are requested to be as brief as possible. The voriter's name is in all cases required as proof of good faith.

On request in advance, one hundred copies of the number containing his communication will be furnished free to any correspondent.

The editor will be glad to publish any queries consonant with the character of the journal.

\section{An Upright-Walking Lizard.}

I REMEMBER reading, some time ago, a report of the discovery of the fossil remains of a large lizard-like creature which must have walked upright on its hinder limbs. The saurians which made the footprints found in some sandstone formations probably walked in the same manner. But it may not be generally known that at least one existing species of lizard habitually runs erect on its hind-legs. This little fellow I noticed, in May, 1891, on the Mojave Desert of California, between Mojave and Death Valley. $\mathrm{He}$ is about one foot in length, of color varying from pale yellow to orange. His forward limbs are short and slender. While feeding, he holds his food in his fore-paws, much as a squirrel holds a nut. While seeking food, or resting, he remains on " all fours," but on starting off, especially if frightened, he rises on his hinder legs and runs away very swiftly, the action of the legs having a ridiculous resemblance to those of a small boy "in a hurry." I have seen one of these lizards run in this manner for thirty or forty yards.

New York, Sept. 8.

C. W. KEMPTON.

\section{The Application of Concussion to Suspended Mist.}

Professor H. A. Hazen's recent criticism of the rain-making experiments seems well-timed. As Espy made important additions to the theory of latent heat as applied to the uprising moist air in cyclones, would it not be well to try the experiment of successive concussions upon suspended mists. If very small drops of rain collect upon a window pane any sudden jar will cause the small drops to coalesce into large drops. Then why is it not pos- sible to produce a like effect upon small floating rain particles? The concussion from a lightning flash usually results in an immediate downpour. By all means let those who have experimented come forward with the results. WILLIAM A. EDDY.

Bergen Point, N.J., Sept. 5.

\section{AMONG THE PUBLISHERS.}

The S. Carson Company, San Francisco, have just published "Forensic Eloquence," by John Goss, a treatise on the theory and practice of oratory as exemplified in great speeches of famous ora tors.

- D. C. Heath \& Co., Boston, have issued "A Brief Spanish Grammar," by Professor Edgren of the University of Nebraska.

- Professor W. S. Chaplin, professor of engineering at Harvard University since 1880, has been elected chancellor of Washington University of St. Louis.

- The Tragedy of the Cæsars" is the title of a new work by the Rev. S. Baring Gould that Methuen \& Co. have in the press and hope to issue shortly. It will be illustrated from busts, gems, cameos, etc.

- Houghton, Mifflin, \& Co. will publish on the 12th the first two volumes of the new large-paper edition of the works of Oliver Wendell Holmes; and a new cheaper edition of S. P. Langley's "The New Astronomy."

- Major Wissmann's new book of African travel from the Kongo to the Zambesi, in the years 1886 and 1887, which he calls "My Second Journey Through Equatorial Africa," will be published in England by Chatto \& Windus. The volume will contain a map and nearly a hundred illustrations.

- Messrs. Macmillan \& Co. intend to publish soon a series of popular sketches on the history of astronomy from the earliest times to the present day, in the form of a volume containing three courses of lectures on astronomical biographv by Professor Oliver Lodge, F.R.S. The work will be fully illustrated, and will bear the title "Pioneers of Science."

- The assiduous biographer of Dr. Johnson, James Boswell, would certainly approve of the devotion of his own biographer, Mr. Percy Fitzgerald, who has written a "Life of James Boswell," which is to be published shortly by D. Appleton \& Co. Mr. Fitz gerald has made a book full of anecdotes. It will contain portraits of Boswell and of Dr. Johnson.

- Charles Scribner's Sons have in preparation a series of concise biographies of the men whose systems have marked successive stages in the progress of education, from Aristotle to Dr. Arnold. It will be edited by Professor Nicholas Murray Butler of Columbia College. Mr. Thomas Davidson will undertake Aristotle; J. G. Fitch, Pestalozzi; J. Courthope Bowen, Fraebel; Professor Butler, Horace Mann.

- The recently completed fifth edition of Dr. M. Foster's well known "Text-Book of Physiology" will be followed at once by the appearance of a sixth and cheaper edition of the work in parts, carefully revised throughout by the author. The addition of much new matter to this edition of the book will permit of taking out a copyright on the American edition, which is to be published by Macmillan \& Co.

- Roberts Brothers will publish soon a new volume in Miss Wormeley's series of translations from Balzac's works, entitled "An Historical Mystery," being one of the "Scenes from Political Life;" a complete edition of Burnand's " Happy Thoughts," and the first American edition of the same author's "More Happy Thoughts;" the third volume of Renan's "History of the People of Israel," treating the subject from the time of Hezekiah till the return from Babylon; and "Four and Five," by Edward Everett Hale, which is a continuation of the "Ten Times One" series.

- The aim of "The Transition-Curve Field-Book," by Conway R. Howard, C.E. (New York, Wiley), is to furnish plain, practical rules and examples for guidance in adjusting and locating a curve, nearly identical with the cubic parabola, as a transition-curve in connecting circular railway curves with tangents. The work is 


\section{Science}

\section{An Upright-Walking Lizard}

C. W. Kempton

Science ns-18 (449), 151

DOI: $10.1126 /$ science.ns-18.449.151

ARTICLE TOOLS

PERMISSIONS http://science.sciencemag.org/content/ns-18/449/151.1.citation

http://www.sciencemag.org/help/reprints-and-permissions 